condition, by the simple removal of two chocks, which lock the wheels in working position, reducing the labor to be done in the coverting department on a red hot vessel to the minimum.

Steelton, June 10, 1882.

\title{
ON THE PREVENTION OF FIRES IN THEATRES.
}

\section{By C. JohN Hexamer.}

[A paper read at the Stated Meeting of the Franklin Institute, held June 21, 1882.]

(Concluded from page 134.)

But plugs should not be solely relied upon for protection in theatres, from the fact that their usefulness depends entirely upon the courage of the employes. It is too much to ask a man to stand and fight fire when he knows that there is a tinder-box between himself and safety, and that at any moment a drifting spark may cut off his only chance of escape. Sometimes such heroes do exist, who pay for their bravery with their lives, but these are only warning examples to others not to risk their own in similar efforts.

In this case we must again take our resort to automatic means, and for this purpose automatic sprinklers, which have been in use in mills for some time, would be of great value.

As a plentiful supply of water is not always at hand, and as steampumps frequently get out of order, large reservoirs should be placed on top of theatres. 'These should be placed on top of the auditorium and not in the rigging-loft. The stage, as the most inflammable part, being generally ignited first, would (if the reservoirs were placed on it) deprive the remainder of the building of water.

In order to keep the water in these tanks from freezing, the exhauststeam pipe of the engine should be made to pass through it; or, as this is not always convenient, it should be mixed with salt (salt water having a lower freezing-point than pure water). The addition of salt would also have the wholesome effect of preventing the formation of algæ (the green slime found on ponds and other still water), which are obnoxious by their smell and by the tendency they have of closing the pipes.

Every theatre should have a fire brigade consisting of at least five 
men ; these should be present at all performances, and should be perfectly familiar with the theatre and all its fire appliances.

At Carlsruhe (the seat of the famous polytechnic school) the authorities, after the great fire of the "Hoftheater," organized a fire patrol of students. These are stationed all over the theatre, know all appliances, and, as a corps of gentlemen, must be much superior to ignorant men, both in case of fire and in quieting a panic.

Watchmen should be constantly on the premises, and, to control them, watch-clocks should be fixed in different parts of the building.

Automatic fire-alarms, placed in various parts of the stage, would be of great use, as the fire department is generally notified too late.

We now arrive at the most important question: The safety of audiences.

From the numerous accounts of theatre fires which the author has collected he finds that loss of life is caused by (1), suffocation by smoke; and (2), the crushing and trampling of the panic-stricken masses.

Experience shows that death is mostly caused by suffocation, and that the burning of bodies is a subsequent occurrence, taking place after life has already become extinct. This was again clearly illustrated by the late Vienna fire, as will be seen from the following account of a civil engineer, given at the time, in several Vienna papers:

"This gentleman, with his wife, was sitting in the second gallery, and, fortunately for himself, was one of the first to discover the fire; they quickly got up and walked out, while the majority of the audience had no idea of the occurrence. The lights were burning until they reached the last steps of the second story, when all lights were suddenly extinguished. While they were still in doubt in what direction to go, they were carried, by a sudden rush, to the right, and found themselves in front of a glass door. This door was broken open, when ther saw that they were, with some twenty-five other persons, on the balcony fronting on the 'Hessgasse' (Hess Street).

"The gentleman, seeing his wife safe, returned to the corridor and loudly shouted: 'This way for safety!' He received no answer. He then went further, until checked by the smoke, but already, at this short distance, saw several corpses. Thereupon he went back to the balcony and saved himself by jumping on the cloths in the street.".

He concludes from this that after this short time, already, every one in that gallery was suffocated. Although we cannot tell how long it took to suffocate all these people, we can safely state that they were 
suffocated and not burned to death, the bodies having been burnt later.

We must, therefore, get rid of the smoke in the quickest and best manner possible. This question has been solved by the ingenious device of Hofman, which acts in conjunction with his automatic drop curtain, and by Mr. Louis Sues of Chicago.

The intense smoke in the auditorium, during a fire on the stage, is caused by a draft of hot air from all parts of the house towards the open doors and ventilator.

The latter is usually situated above the main chandelier in the centre of the auditorium ceiling. This draft may frequently be noticed by the sail-like outward bulging of curtains.

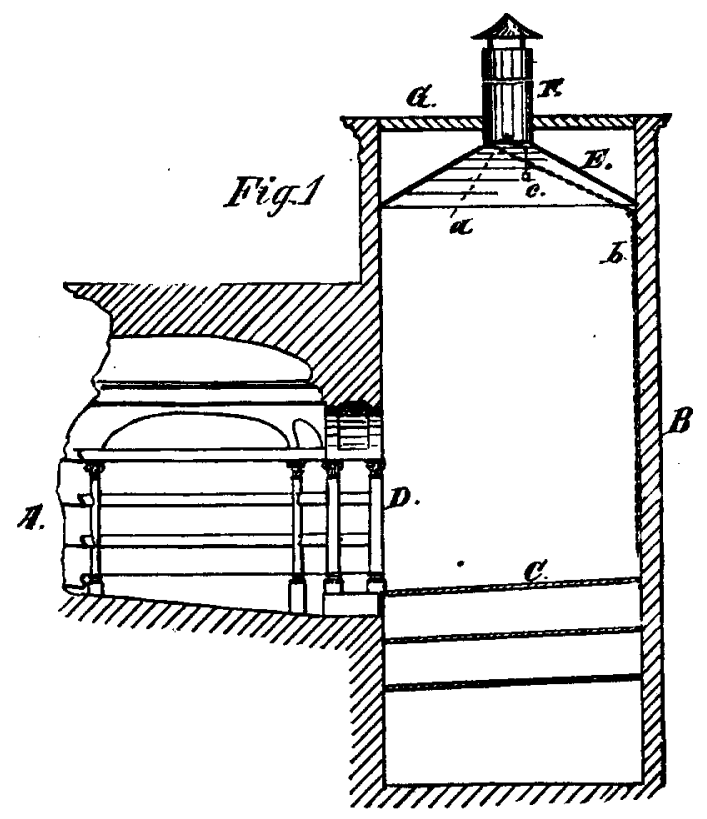

We must, therefore, form a counter draft which, in case of fire, would be strong enough to overcome the combined action of the doors and ventilator.

This could best be accomplished by a chimney or flue on the top of the stage which would take off all smoke and cinders. Or, as before stated, making a perfect shaving vault of the stage.

We will now describe the different solutions advanced for this problem, beginning with the simplest. 
A good idea was suggested a short time ago by one of the inspecting chiefs of the New York fire department. It was, to make the roof over the stage a vast skylight, the glass of which could be broken in case of fire and a draft thus created which would carry the flames upwards and prevent them spreading to the auditorium.

Next in order comes Mr. Sues' smoke flue, the description of which I quote from his patent specification. Fig. 1 is a vertical section. Fig. 2 is a detail in perspective.

"Theatres frequently take fire and in almost all cases the fire originates in that portion of the building devoted to the stage and scenery. There is usually a draft from the stage to the auditorium, especially when the doors are opened and the flames and smoke pass rapidly from the stage to the audience room.

"The object of my inventions is to construct theatres so that this difficulty will be obviated to a great extent, and it consists in a large outlet in the roof over the stage for the passage of smoke in case of fire, so that a current of air will be induced from the auditorium to the stage instead of from the stage to the auditorium, and combining with such outlet a ceiling over the stage portion of the building which will for a considerable time resist the action of fire, thus giving the audience time to escape.

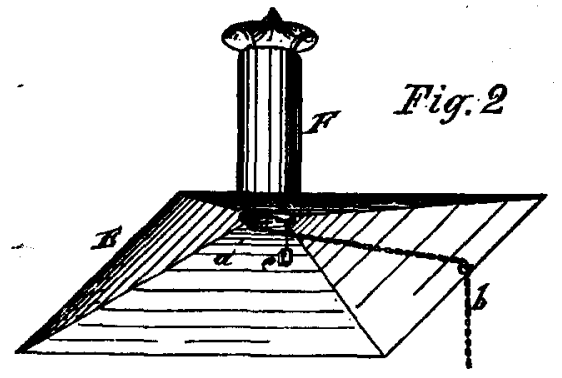

"In the drawings, $A$ indicates the auditorium; $B$ that portion of the building devoted to the stage; $C$, the stage; $D$, opening between the stage and the anditorium; $E$ is the ceiling over the stage. This ceiling I make practically fire-proof, either by making it wholly of metal or by the use of metal joists with wire or wire-cloth for lathing, and usual plastering, or in other suitable manner. $F$ is a large passage to be made of fire-proof material. It passes through the roof $G$. Its lower end is properly secured in the ceiling and is open, except when closed by the valve $a$. $b$ is a chain by means of which the valve $a$ 
can be opened. $c$ is a weight which holds the valve in position when elosed.

"The operation is as follows: If a tire breaks out upon the stage the valve $a$ is to be immediately opened. The ascending heat and smoke will rise to the ceiling and escape through $F$, thereby producing a current from the auditorium to the stage, instead of the reverse, thus keeping the smoke and flames from the audience-room while the audienee is escaping. In cases where a fire-proof drop-curtain is used suitable openings may be somewhere provided to admit air to the stage.

"In theatres of the usual size the passage $F$ ' should be about six feet in diameter. It may be carried some distance above the roof which will increase the draft.

"Two or more of these passages $F$ may be used. The opening at the top of the passage $F$ may be protected from storms by caps."

This is an excellent device, the only objection to it is that it is not automatic; its usefulness, in case of fire being, therefore, dependent on the coolness of the men having it in charge.

The ingenious device of Hofnan combines an antomatic wire dropcurtain, and automatic smoke flue and an automatic fire alarm. This device will act without the aid of a single hand, being entirely automatic.

It consists of a safety-rope, which runs on pulleys over the principal and most dangerous parts of the stage. This rope is prepared so as to be the most combustible substance on the stage. In case of fire, it will, therefore, ignite and burn off almost instantly. Has this moment arrived, a heavy weight, held by the safety-rope, falls. This weight being connected with the machinery of the curtain by a lever, the lever is raised, the machinery set in motion, and the curtain lowered. Not, however, with a sudden fall which might damage it, but steadily.

The falling of the heavy weight, at the same time, opens the valve of the large smoke flue contained in the roof of the stage, whereby the smoke and heat of the fire is kept on the stage and taken out of the flue; thus giving the audience time to leave the theatre quietly and orderly, without being threatened by smoke or heat. The same moment the above takes place the fall of the weight sets a fire alarm in motion and the fire department is notified.

We have now seen the different devices for getting rid of that greatest danger to audiences-smoke-and can now compare their 
relative values. The first would be very simple, but in the time required for the firemen to arrive and break in the glass of the skylight, the audience might be suffocated.

The second is an excellent patent, its only objection being, as before stated, its want of automatism.

The third, to the author, seems undoubtedly the best, for if in case of fire, the men having it in charge should neglect to open the valve, it would act automatically; not to speak of the immense value of the automatic wire drop-curtain and fire-alarm.

The writer has frequently noticed the time required by audiences to vacate theatres, and out of numerous experiments finds it takes from $3 \frac{1}{2}$ to 11 minutes for a theatre to be entirely emptied. But this time is protracted indefinitely in case of a panic. It has been found that in cases where audiences had ample time to vacate theatres many were killed, although not prevented from escaping by the smoke.

This is explained by the jamming of crowds in corridors. A mass of people may best be compared with a number of logs floating down a stream, which at some point, by their mutual pressure, form arches across it, thus becoming wedged fast. In the same manner persons form arches across corridors which are sometimes broken, only to be formed again.

This, the cause of many deaths, may be remedied by making the walls of corridors inclined towards each other, being narrowest in the theatre and widening towards the exit doors, as it is impossible for logs to jam in a widening water-course.

There should be outlets from each gallery or floor separate and distinct from every other outlet, so that a crowd from one gallery cannot precipitate itself upon a crowd from another floor that is struggling to get out,

A matter still sometimes neglected is, that all doors should open outwards, the people of the fourth gallery at the recent Vienna fire, for example, were hindered from flight by the doors opening inwards.

Most theatres have a sufficient number of exits, but in order to save doorkeepers most of them are locked; some not being satisfied with locking them, even nail and bolt them shut.

Corridors are also frequently too narrow ; these should never be less than eight feet broad, which would allow, at most, but five persons abreast.

Another outrage to humanity are high galleries. In American 
theatres there are never more than three, but in Europe they have as many as five.

Law should forbid the ereetion of more than two galleries, i. e., a "balcony" and "family circle."

The horrors of theatre fires are always increased by the total darkness which envelopes audiences a short time after commencement of the fire.

This is frequently caused by the explosion of gas on the stage. To obviate this, all theatres should separate the system of lighting the auditorium from that of lighting the stage.

After years of hard work, the authorities of Vienna succeeded in compelling managers to have oil lamps in corridors. The order was complied with, but, as was seen by the late catastrophe, these were never lighted.

It has frequently been urged, especially by "insurance men," that the risk from fire would only be increased by the use of coal oil in these lamps. But it is not necessarily said that petroleum must be used, for any of the heavy oils (used long before coal oil was known) might be employed with advantage.

If these should be objected to, let it be remembered that festivals which outrival everything in history by their splendor, and that the plays of a Corneille and a Moliere were first produced before the eyes of the then most powerful king of Europe, by the light of candles. Why should these then not satisfy us in the humble position of safety corridor lights?

Particular attention should be paid to the calamity at Carlsruhe in 1847. By the inattention of one of the servants in lighting the gas the drapings of the Grand Ducal box caught fire. All parts of the house were crowded, over 2000 persons being present. The flames instantly spread to the balcony; every one tried to escape in the greatest hurry. The audience of the parquet, as well as that of the balcony, saved themselves, but the greatest confusion ensued in the higher galleries which were in a short time filled with smoke.

Of the four exits, but the one under which the fire broke out was open. Every one rushed to this exit and very soon it was jammed shut. The scenes following were indescribable: A few climbed or jumped from the galleries; others threw themselves out of the windows; many were crushed to death, and most were suffocated by the hot smoke. 
In the narrow corridors people were lying in heaps. To this was added that immediately after the breaking out of the fire the gas was turned off from the street and the building thrown into total darkness. The situation of the people, jammed fast in corridors, without light, enveloped in smoke, was frightful.

This catastrophe cost the lives of sixty-three persons, and over two hundred were terribly wounded.

As before mentioned, the theatre had four exits, but to save the expense of extra doorkeepers three of these had been closed for years, and not only locked, but nailed and boarded shut, and but few knew the exIstence of these extra exits.

One cause saved the lives of many-gas had not long ago been introduced and on this account many oil lamps had been retained to do duty in corridors. These lamps, which had been the objects of wit and sarcasm, saved the lives of hundreds.

We had at Vienna the counterpart of Carlsruhe, only in this case the lamps were not lighted or hundreds of unfortunate victims would have been saved.

It can, from this, be seen how necessary oil lamps are and that in the deciding moment this precaution will save many lives.

Before concluding my remarks it may be well for me to give an example of a theatre, which was managed in the correct manner, which had many of the modern improvements, and which at the same time is the first case on record in which the entire audience of a burning theatre escaped in safety. On the 16th of April, of this year, during a performance of the farce "Robert and Bertram," at the "HofTheater" of Schwerin, the cry of fire was suddenly heard from one of the galleries. As no flames or smoke were perceived the andience remained seated, until the news came from the outside that the roof was burning. The Grand Duke, who was present immediately addressed a few words to the audience and ordered the musicians to continue. The stage-manager also assured the audience that there was no danger. But soon the wire curtain had to be lowered, and now the audience left the theatre in the greatest order, especially the densely packed galleries were rapidly cleared, the audience escaping through the numerous exits, which were all open. For some time previous to the occurence audiences had been instructed-by means of large placards hung up in the corridors-how to act in case of fire. The oillamps were all lighted, and the wire-curtain was in good working order, 
thus for the first time, practically illustrating its use. On account of these excellent arrangements it was possible for the whole audience to save itself, although many ladies and children were present. Here we then have an example to show how, with proper precautions, faithful employés-especially the man who let down the wire-curtain-and cool, collected conduct, an audience may be spared the dangers of a theatre-fire. The beautiful theatre burned down, also the large Concert Hall attached to it. But the only life lost in the event was that of a fireman who was buried under a falling wall, this occurring a considerable time after the audience had escaped.

The author hopes to have shown how theatres can be built, although not fire-proof, yet in a manner so as to give safety to audiences.

Theatres could and should be built so that the largest audiences could escape in safety.

\section{THE CHEMISTRY OF THE PLANTE AND FAURE ACCUMULATORS.}

\section{By J. H. Gladstone and Alffred Tribe.}

Part I.-Locai. Action.

Among the important discoveries of late years few have claimed so much attention, or have been so full of promise for practical use, as the accumulator of Planté and its modifications. Our attention was very naturally directed to the chemical changes that take place in these batteries, especially as it appeared to us that there must be certain analogies between them and some actions which we had previously investigated. In the present communication we propose to treat merely of one point-that of local action, leaving the fuller discussion of the subject to some future occasion.

It is well known that metallic zinc will not decompose water even at $100^{\circ} \mathrm{C}$, but we found that zinc, on which copper had been deposited in a spongy condition, was capable of splitting up the molecule even at the ordinary temperature, oxide of zinc being formed and hydrogen liberated. If placed in dilute sulphuric acid it started a very violent chemical action, sulphate of zinc and hydrogen gas being the result. We termed the two metals thus conjoined, the copper-zinc couple, and this agent was fruitful in our hands in bringing about other chemical 